\title{
Faunistic study on scorpions and their health impact in Bashagard County, Hormozgan Province, Southern Iran
}

\author{
MEHRAN SHAHI ${ }^{1}$, SEYED AGHIL JABERHASHEMI ${ }^{2}$, AHMAD ALI HANAFI-BOJD ${ }^{3}$, MORTEZA AKBARI ${ }^{4}$, \\ JAVAD RAFINEJAD ${ }^{3, \bullet}$ \\ ${ }^{1}$ Department of Medical Entomology and Vector Control, School of Public Health and Infectious \& Tropical Diseases Research Center, Hormozgan \\ Health Institute, Hormozgan University of Medical Sciences, Bandar Abbas, Iran. \\ ${ }^{2}$ Department of Diseases Control, Hormozgan University of Medical Sciences, Bashagard, Iran \\ ${ }^{3}$ Department of Medical Entomology and Vector Control, School of Public Health, Tehran University of Medical Sciences. Tehran, Iran. \\ vemail jrafinejad@yahoo.com \\ ${ }^{4}$ Department of Public Health, School of Health, Ilam University of Medical Sciences. Ilam, Iran
}

Manuscript received: 14 February 2021. Revision accepted: 12 April 2021.

\begin{abstract}
Shahi M, Jaberhashemi SA, Hanafi-Bojd AA, Akbari M, Rafinejad J. 2021. Faunistic study on scorpions and their health impact in Bashagard County, Hormozgan Province, Southern Iran. Nusantara Bioscience 13: 85-90. Scorpion sting is a major public health problem in tropical and subtropical countries, endangering thousands of lives annually. About 2300 scorpion sting cases including several deaths are reported from Hormozgan Province annually. This study aimed to determine the fauna of scorpions and epidemiological aspects of scorpion sting in one of the high-risk areas in this province. Scorpions were collected by diurnal searching and night catch using UV light during 2015-2016. Clinical and demographic data of scorpion sting were obtained from Hormozgan Health Center using the checklist of the Center for Disease Control (CDC) archive during the study period. Data analysis was performed using SPSS 21 software. A total of 382 scorpions comprising of 9 species belonging to Buthidae (76\%) and Hemiscorpiidae (24\%) families were collected and identified as Mesobuthus phillipsi, Androctonus crassicauda, Hottentotta sistanensis, Compsobuthus persicus, Hemiscorpius acanthocercus, Orthochirus farzanpayi, H. acanthocercus, and Odontobuthos sp. The most abundant species in the study area was M. phillipsi. During 2015-2016, a total of 1221 scorpion sting cases including four deaths were recorded in Bashagard County, while most of the cases occurring during summer. The climate of the eastern regions of Hormozgan Province provides a suitable habitat for one of the deadliest genera of scorpions, i.e. Hemiscorpius. This genus is the main cause of death due to scorpion sting in these regions. It is thus necessary to design appropriate programs for the prevention and treatment of scorpion sting, including health education programs for both community members and healthcare personnel.
\end{abstract}

Keywords: Faunistic, scorpion sting, Hemiscorpius, health, Iran

\section{INTRODUCTION}

Scorpion sting is a major public health problem in tropical and subtropical countries, which endangers thousands of lives annually. Factors such as geographic location, lifestyle, socioeconomic status, housing, health care, and the type of scorpion species native to each geographical area have variable effects on the incidence of a scorpion sting ( Kassiri et al. 2012). Most of the deadly scorpions are found in North Africa, the Middle East (Androctonus, Buthus, Hottentotta, and Leiurus), India (Mesobuthus), America (Tityus), and Mexico (Centruroides) (Prendini and Wheeler 2005). Species diversity and distribution of scorpions are affected by the climatic conditions of each geographical area. Information on the distribution of scorpion species in some areas of Iran is very limited.

Most of the cases of death due to scorpion stings are reported from the southern and southwestern areas of the country (Dehghani et al. 2010; Vazirianzadeh et al. 2013; Mousavi et al. 2015). Khuzestan, Hormozgan, and Kerman provinces are the most important foci of scorpion sting in the southern part of Iran, and several cases of death due to scorpion sting reported in these provinces every year (Radmanesh 1990; Pipelzadeh et al. 2007; Dehghani and Fathi 2012; Mousavi et al. 2015; Dehghani et al. 2016; Shahi et al. 2016). Androctonus, Hottentotta, Mesobuthus, Odontobuthus, and Hemiscorpius genera are the dangerous scorpions to humans found in the southern part of Iran (Jalali et al. 2010).

Hormozgan Province is among the high-risk zones of scorpion sting. Previous studies found 22 scorpion species in this province (Navidpour et al. 2013; Shahi et al. 2016). Hemiscorpius species such as $H$. acanthocercus, $H$. enischnochela, $H$. gaillardi, H. persicus, and H. lepturus are the most lethal scorpions in this Province (Shahi et al. 2015;2016). Nevertheless, little information is known about the fauna and distribution of scorpion species in some highrisk areas in the south of the country. Annually, about 2300 scorpion sting cases including several deaths are reported in Hormozgan Province. This study was designed to identify the deadliest scorpion species and their distribution in Bashagard County in the Northeast of Hormozgan Province, as well as the epidemiological aspects of scorpion stings in this area. 


\section{MATERIALS AND METHODS}

\section{Study area}

Bashagard County, located in the east of Hormozgan Province, Iran (Figure 1) consists of three rural districts, two cities, and 166 villages. According to the 2016 census in the country, Bashagard County has a population of 40,007 people. The center of this county, Sardasht, is located at $26^{\circ} 21^{\prime} \mathrm{N}$ and $57^{\circ} 54^{\prime} \mathrm{E}$. This county is $1480 \mathrm{~m}$ above sea level (ASL) and has a land area of $9,209 \mathrm{~km}^{2}$. It is located in a mountainous area with a dry and hot climate. The average rainfall in this county is about $200 \mathrm{~mm}$ per year, and the minimum and maximum temperatures range between 7 to $45^{\circ} \mathrm{C}$. The study was conducted in five main sites, selected based on geographical direction including north, south, east, west, and the center of Bashagard county. Geographical coordinates of the five main study sites are as follow: Goharan: $26^{\circ} 36^{\prime} 13.42^{\prime \prime} \mathrm{N}, 57^{\circ} 53^{\prime}$ 16.67" E, 941.56 m ASL; Gafr: $26^{\circ} 14^{\prime} 18.54^{\prime \prime} \mathrm{N}, 58^{\circ} 12^{\prime}$ 40.63" E, 564.44 m ASL; Paramon: $26^{\circ} 29^{\prime} 27.38^{\prime \prime} \mathrm{N}, 58^{\circ}$ $15^{\prime} 2.61 "$ E, 842.42 m ASL; Jagdan: $26^{\circ} 26^{\prime} 12.35^{\prime \prime} \mathrm{N}, 57^{\circ}$ 44' 20.11" E, 908.48 m ASL; Sardasht: $26^{\circ} 27^{\prime} 33.06^{\prime \prime} \mathrm{N}$, $57^{\circ} 54^{\prime} 1.52 \mathrm{E}, 716.57 \mathrm{~m}$ ASL (Figure 1).

\section{Scorpion samplings}

Scorpions were collected from their habitats by diurnal searching and night catch using UV light, between September 2015 and October 2016 (Figure 2). The specimens were preserved in 75\% ethanol alcohol and kept in the Medical Entomology laboratory of Bandar Abbas Health School. Geographical coordinates were recorded by a GPS device $\left(\operatorname{Garmin}^{\mathrm{R}}\right)$. Scorpions were identified using an identification key (Navidpour et al. 2013) in the Medical Entomology laboratory of Bandar Abbas Health School, Hormozgan University of Medical Sciences.

\section{Scorpion sting data}

Clinical and demographic data of scorpion sting were obtained using the checklist of the Center for Disease Control (CDC) archive in Hormozgan Health Center during 2015 and 2016. Demographic data included sex, age, geographic location, site of the sting, and patient outcome. Data analysis was performed using SPSS 21 software, and graphs were drawn using Excel.
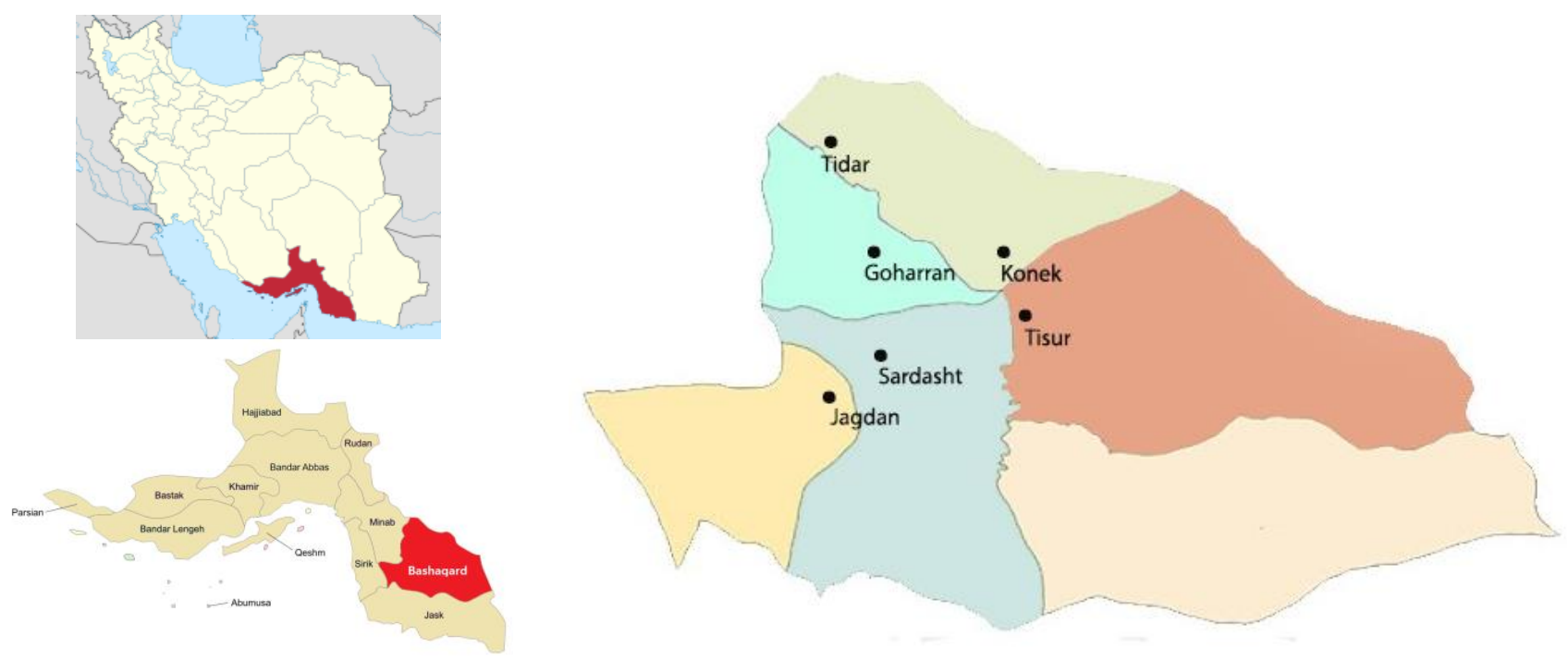

Figure 1. Map of study area in Bashagard County, Hormozgan Province, southern Iran

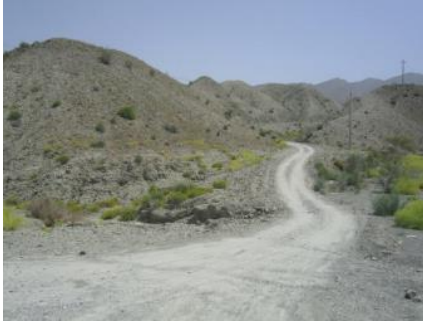

A

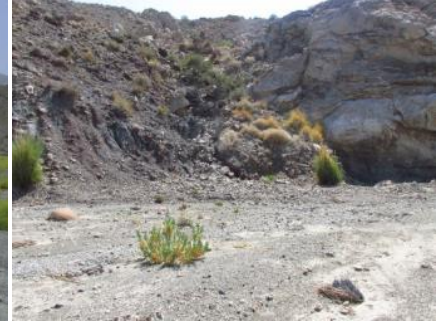

B

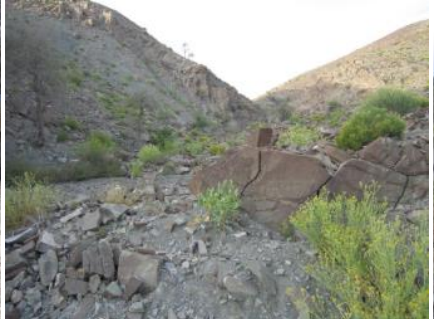

C

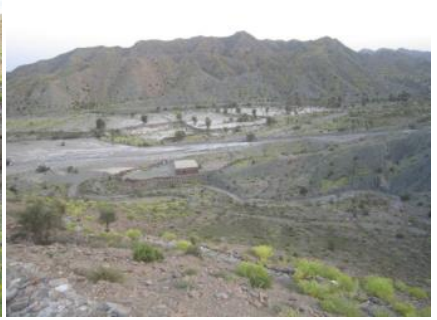

D

Figure 2. Natural habitats of scorpions in the study area, Bashagard County, Hormozgan Province, southern Iran. A. Compsobuthus, B. Hottentotta, Hemiscorpius, C. Hemiscorpius, Mesbuthus, Orthochirus, D. Odontobuthus 


\section{RESULTS AND DISCUSSION}

A total of 382 scorpions comprising 9 different species belonging to Buthidae (76\%) and Hemiscorpiidae (24\%) families were collected and identified. M. phillipsi $(\mathrm{N}=126)$ was the most abundant species in the study area, and $A$. crassicauda $(\mathrm{N}=1)$ and $O$. bidentatus $(\mathrm{N}=2)$ were the least abundant species (Figure 3). Mesobuthus $(\mathrm{N}=178)$ was the most dominant genus. The percentage of male $(\mathrm{N}=254)$ and female $(\mathrm{N}=128)$ scorpions were $66.5 \%$ and $33.5 \%$, respectively. We identified $H$. schach $(\mathrm{N}=15)$, C. persicus $(\mathrm{N}=8), H$. acanthocercus $(\mathrm{N}=109)$, and O. farzanpayi $(\mathrm{N}=21)$ for the first time in Bashagard County. Mesbuthus phillipsi, $H$. acanthocercus, and $O$. doriae were the most widely distributed species. H. acanthicercus was collected in all sampling sites (Figure 3).

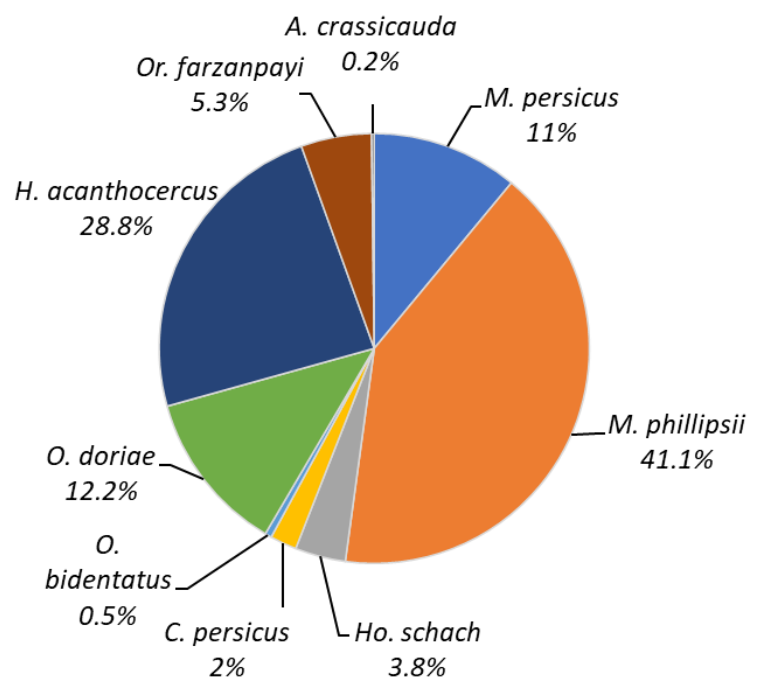

Figure 3. Species composition of scorpions in Bashagard County, Southern Iran, 2016
During 2011-2015, a total of 1221 cases of scorpion sting were recorded in the health center of Bashagard County including four deaths. Figure 4 shows scorpion sting cases in different months, with the highest number of cases being recorded in August (Table 1).

About $96.4 \%$ of cases occurred in rural areas, whereas only $3.6 \%$ occurred in the urban areas $(\mathrm{P}<0.05)$. Females $(59.6 \%)$ were stung more than males $(40.4 \%)$ during the study period $(\mathrm{P}<0.05)$. Table 1 shows the frequency of scorpion stings in different age groups. Most of the scorpion sting cases occurred in the age group 10-24 years $(\mathrm{P}<0.05)$.

Figure 5 shows the most common sites of scorpion sting. The foot of patients represented the most common site $(38.4 \%)$ for scorpion stings (Figure 5).

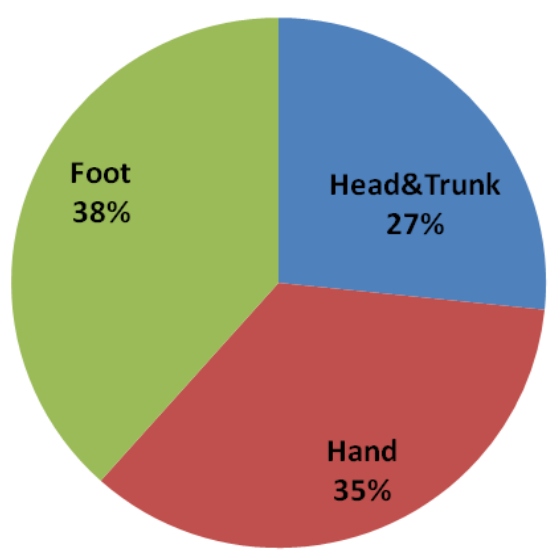

Figure 5. Scorpion sting in different parts of the body, Basaghard county, Southern Iran, 2011-2015

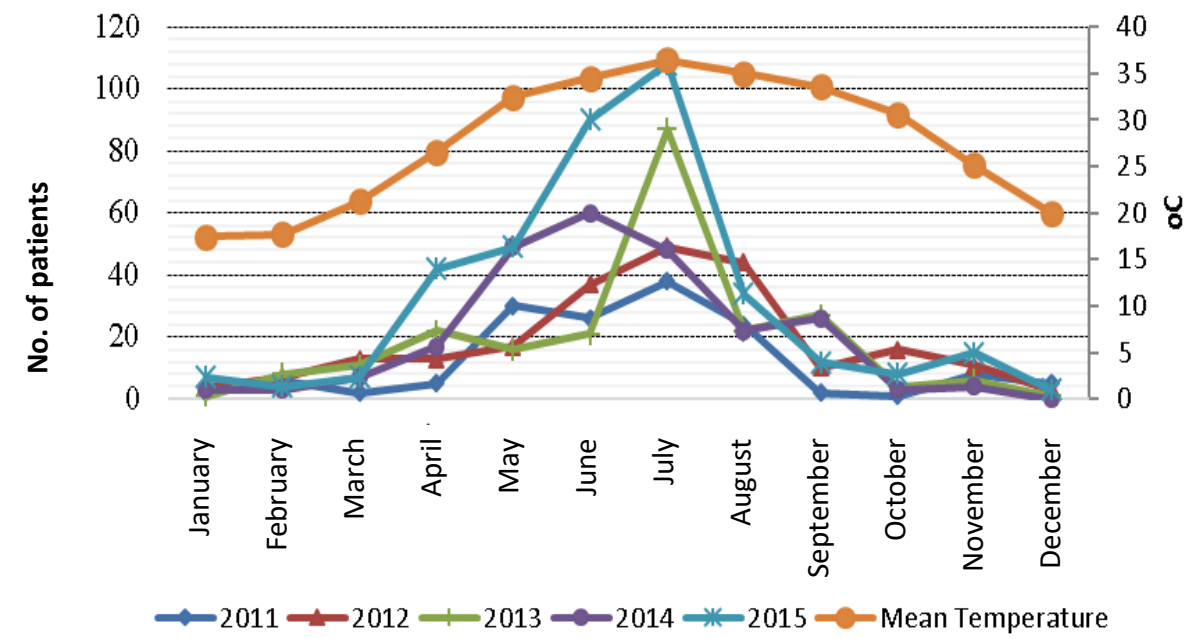

Figure 4. Monthly scorpion sting cases in Bashagard County, Southern Iran, 2011-2015 
Table 1. Scorpion sting in different age groups, Bashagard County, Southern Iran, 2011-2015

\begin{tabular}{lcccccc}
\hline \multirow{2}{*}{ Year } & \multicolumn{7}{c}{ Age group } & \multirow{2}{*}{ Total } \\
\cline { 2 - 6 } & $\boldsymbol{< 9}$ & $\mathbf{1 0 - 2 4}$ & $\mathbf{2 5 - 4 4}$ & $\mathbf{4 5 - 6 4}$ & $>\mathbf{6 5}$ & \\
\hline 2011 & 19 & 65 & 32 & 22 & 11 & 149 \\
2012 & 44 & 85 & 53 & 30 & 13 & 225 \\
2013 & 42 & 88 & 63 & 21 & 12 & 226 \\
2014 & 61 & 65 & 70 & 30 & 16 & 242 \\
2015 & 74 & 130 & 107 & 53 & 15 & 379 \\
Total & 240 & 433 & 325 & 156 & 67 & 1221 \\
Percent & 19.60 & 35.50 & 26.60 & 12.80 & 5.50 & 100 \\
\hline
\end{tabular}

\section{Discussion}

The Southern part of Iran is an important region for scorpion sting. Bashagard County is one of the important foci in this region. In 2015, 329 cases of scorpion stings were reported, resulting in 2 deaths $(0.61 \%)$. The estimated annual number of scorpion stings in the World is 1.2 million leading to 3250 deaths $(0.27 \%)$ (Chippaux and Goyffon 2008). This report indicates that the mortality rate of scorpion sting is high in this county. In some of the cases, the scorpion species that stung the victims could not be identified, and some of the deaths might have resulted from the sting of unknown dangerous scorpion species in this county.

Hemiscorpius acanthocercus is one of the most important and deadly scorpion species, which we identified for the first time in the study area. In some other studies, M. phillipsi was identified as the most abundant species followed by $H$. acanthocercus in Hormozgan Province (Monod and Lourenco 2005; Shahi et al. 2016). A case of death due to $H$. acanthocercus sting has been reported in Bandar Abbas County (Shahi et al. 2015).

Hemiscorpius lepturus is the deadliest scorpion species in the west and south areas of Iran ( Radmanesh 1990; Ahmadizadeh and Razi-Jalali 2006; Shahi et al. 2009; Zare et al. 2011; Mohseni et al. 2013). Hemiscorpius lepturus envenomation is the main cause of death in the Khuzestan Province of Iran (Rahmani and Jalali 2012; Vazirianzadeh et al. 2013). Hemiscorpius scorpions are widely distributed in the Western and Southern regions of the country (Navidpour 2015; Shahi et al. 2015; Dehghani et al. 2016).

In our study, $M$. phillipsi was the most abundant species. In some studies, conducted in other provinces, Mesobuthus genus was reported as the most dominant genus in the study areas (Azizi et al. 1998; Dehghani et al. 2008; Nejati et al. 2014; Dehghani et al. 2016). It seems that the climate of the southern areas in Iran provides suitable habitat for species belonging to this genus.

Odontobuthus, a digger scorpion species, was identified in all sampling sites in our study. Other scorpion genera identified in our study include Odontobuthus, Orthochirus, Hottentotta, Compsobuthus, and Androctunus. Odontobutus, Hottentotta, and Androctonus are the deadly scorpions in Iran (Dehghani et al. 2008; Nazari and Hassan 2016).

Hottentotta schach was the largest scorpion observed in our study area. The existence of this scorpion in Fars and
Khuzestan provinces has been reported (Kovařík 2007; Navidpour 2012; Vazirianzadeh and Salahshoor 2015). This species has limited distribution in Iran, and we identified it for the first time in Bashagard County in Hormozgan Province.

Based on the diversity of scorpion species identified in the present study, it can be concluded that scorpion fauna is very diverse in Bashagard County. This county is located in mountainous areas. Research studies have shown that mountainous areas have more diverse animal species. The main reason is the existence of many shelters and suitable habitats for animals in these areas. Results of faunistic studies conducted in Iran have shown that mountainous areas have richer fauna compared to plains (Azizi et al. 2001; Haghi et al. 2004; Shahi et al. 2009; Kheirabadi et al. 2014).

About $60 \%$ of the scorpion sting victims in our study were women. This result is consistent with that of another study conducted in the country (Kassiri et al. 2012). In epidemiological studies on scorpion stings conducted in Turkey, Brazil, USA, and Australia, it was observed that females are more susceptible to scorpion sting compared with males (Isbister et al. 2003; Pardal et al. 2003; Forrester and Stanley 2004; Al et al. 2009). Another study, however, reported that men are more commonly stung by scorpions compared with women in a study conducted in Kashan (Dehghani et al. 2010). This difference may be due to the type of social activities engaged by women in different study areas. In traditional rural societies of Bashagard County, women generally do the task of gathering firewood for cooking and performing household chores.

In our study, we observed that cases of scorpion sting were more common in the age group 10 to 24 years. The lowest percentage of stings occurred in patients older than 60 years. The results of the studies conducted by Talebian and Doroudgar (2006), Hoseininasab et al. (2009), and Saghafipour et al. (2013) are consistent with that of our studies. The 10-24-year age group includes active members of society. Job activity increases the risk of scorpion sting among people in high-risk areas.

The most common site of scorpion sting was on the feet $(38.4 \%)$ of patients, followed by hand $(35 \%)$. This result is similar to that of the studies of Pipelzadeh et al. (2007), Shahbazzadeh et al. (2009), and Kassiri et al. (2013) conducted in Iran.

We found that most of the cases of scorpion sting occurred in August and rural areas. In Baghmalek of Khuzestan, $64.8 \%$ of scorpion sting cases were reported in rural regions (Kassiri et al. 2014). Rafizadeh et al. (2013) also reported that $57.7 \%$ of scorpion stings occur in rural areas. The climatic conditions coupled with the activities of the rural dwellers increase the risk of scorpion stings in these areas.

Figure 4 shows an increasing trend in the number of scorpion sting cases in Bashagard County during the study period (2011-2015). Other studies in the country have reported a high number of scorpion sting cases during summer (Dehghani and Fathi 2012; Nejati et al. 2014; 
Khatony et al. 2015). Our result is in agreement with that of other studies conducted in Ramhormoz and Kashan. In Iran, Turkey, and Morocco, there have been reports on a high number of scorpion sting cases during the hot season of the year (Talebian and Doroudgar 2006; Abourazzak et al. 2009; Uluğ et al. 2012; Karami et al. 2013). Scorpions are active in warm seasons, which correlates with the increased number of scorpion stings cases during summer.

The high number of scorpion sting cases in rural areas may also be due to the large number of people living in the villages. The rural to the urban proportion of the study population was 13 to 1 .

In 2015, two cases of death due to scorpion stings were recorded in Bashagard County. The patients presented with severe hematuria, kidney failure, and DIC before death. The victims were aged less than ten years. In a study conducted in Bandar Abbas County in Hormozgan province, Hemiscorpius sting caused hemolysis, hematuria, and renal failure in patients before death (Shahi et al. 2015). Owing to the similarity in the symptoms presented by the patients in Bandar Abbas County and our study area, it seems likely that the cause of death due to the sting of an unidentified scorpion in Bashagard County was due to Hemiscorpius.

This study showed that the eastern regions of the Hormozgan province in southern Iran provide a suitable habitat for one of the most lethal scorpions species, belonging to the Hemiscorpius genus. It seems likely that this genus is the main cause of death due to scorpion sting in these regions. Appropriate public health programs are necessary for the prevention and management of scorpion sting in the study area.

\section{ACKNOWLEDGEMENTS}

We are grateful to Abedini, Infectious and Tropical Diseases Research Center, Hormozghan University of Medical Science, Iran. This study was funded by ViceChancellor for Research and Technology, Hormozghan University of Medical Sciences, Project No. 94140.

\section{REFERENCES}

Abourazzak S, Achour S, El Arqam L, Atmani S, Chaouki S, Semlali I, Soulaymani BR, Bouharrou A, Hida M. 2009. Epidemiological and clinical characteristics of scorpion stings in children in Fez, Morocco. J Venom Anim Toxins incl Trop Dis 15 (2): 255-267. DOI: 10.1590/S1678-91992009000200008.

Ahmadizadeh M, Razi-Jalali M. 2006. The effect of Hemiscorpius lepturus scorpion venom on the level of some biochemical parameters in rat. Biochem Cell Arch 1: 147-155.

Al B, Yılmaz DA, Sögut O, Orak M, Üstündağ M, Bokurt S. 2009. Epidemiological, clinical characteristics and outcome of scorpion envenomation in Batman, Turkey: An analysis of 120 cases. JAEM 8 (3): 9-14.

Azizi K, Shahraki G, Omrani M. 2001. Determination of the fauna and sex ratio of scorpions from villages and suburbs of Kohgilouieh and Boirahmad province in 1379. J Armaghan Danesh 6 (21-22): 6-13.

Azizi K, Tirgari S, Sayedi-Rashti M. 1998. Faunistic study of scorpions in Shiraz and investigation on their fecundity. J Armaghan Danesh 3 (9): 10 .
Chippaux JP, Goyffon M. 2008. Epidemiology of scorpionism: A global $\begin{array}{lllll}\text { appraisal. Acta Trop } 107 & \text { (2): } & 71-79 . & \text { DOI: }\end{array}$ 10.1016/j.actatropica.2008.05.021.

Dehghani R, Fathi B. 2012. Scorpion sting in Iran: A review. Toxicon 60 (5): 919-933. DOI: 10.1016/j.toxicon.2012.06.002.

Dehghani R, Haghi FM, Mogaddam MY, Sedaghat M, Hajati H. 2016. Review study of scorpion classification in Iran. J Entomol Zool Stud 4 (5): 440-444.

Dehghani R, Moabed S, Kamyabi F, Haghdoost A, Mashayekhi M, Soltani H. 2008. Scorpions fauna of Kerman province-Iran. J Kerman Univ Medical Sci 15 (2): 172-181.

Dehghani R, Vazirianzadeh B, Nasrabadi MR, Moravvej SA. 2010. Study of scorpionism in Kashan in central of Iran. Pak J Med Sci 26 (4): 955-958.

Forrester MB, Stanley SK. 2004. Epidemiology of scorpion envenomations in Texas. Vet Hum Toxicol 46 (4): 219-221.

Haghi F, Tirghari S, Çhangani F, Mohammadpour R. 2004. A study on the scorpion species of the mountainous areas of Sari township in 2001. J Mazandaran Univ Sci 14 (43): 92-96.

Hoseininasab A, Alidoosti K, Torabinezhad M. 2009. The epidemiologic status of scorpion bite and its associated ris factors in south of Kerman Province. J Med Counc I R. Iran 3 (27): 295-301.

Isbister GK, Volschenk ES, Balit CR, Harvey MS. 2003. Australian scorpion stings: A prospective study of definite stings. Toxicon 41 (7): 877-883. DOI: 10.1016/S0041-0101 (03)00065-5.

Jalali A, Pipelzadeh MH, Sayedian R, Rowan E. 2010. A review of epidemiological, clinical and in vitro physiological studies of envenomation by the scorpion Hemiscorpius lepturus (Hemiscorpiidae) in Iran. Toxicon 55 (2-3): 173-179. DOI: 10.1016/j.toxicon.2009.09.012.

Karami K, Vazirianzadeh B, Mashhadi E, Hossienzadeh M, Abbas Moravvej S. 2013. A five year epidemiologic study on scorpion stings in Ramhormoz, South-West of Iran. Pak J Zool 45 (2): 469-474.

Kassiri H, Kassiri A, Sharififard M, Shojaee S, Lotfi M, Kasiri E. 2014. Scorpion envenomation study in Behbahan County, southwest Iran. J Coast Life Med 2 (5): 416-420.

Kassiri H, Mohammadzadeh Mahijan N, Hasanvand Z, Shemshad M, Shemshad K. 2012. Epidemiological survey on scorpion sting envenomation in South-West, Iran. Zahedan J Res Med Sci 14 (8): 80-83.

Kassiri H, Shemshad K, Kassiri A, Shemshad M, Valipor AA, Teimori A. 2013. Epidemiological and climatological factors influencing on scorpion envenoming in Baghmalek County, Iran. Acad J Entomol 6 (2): 47-54.

Khatony A, Abdi A, Fatahpour T, Towhidi F. 2015. The epidemiology of scorpion stings in tropical areas of Kermanshah province, Iran, during 2008 and 2009. J Venom Anim Toxins incl Trop Dis 21: 45-52. DOI: 10.1186/s40409-015-0045-4.

Kheirabadi KP, Pirbalouty VK, Jazayeri A. 2014. Geographical distribution of scorpions in Chaharmahal va Bakhteyari Province. Vet J 27 (2): 44-51. DOI: 10.22092/VJ.2014.100982.

Kovařik F. 2007. A revision of the genus Hottentotta Birula, 1908, with descriptions of four new species (Scorpiones, Buthidae). Euscorpius 2007 (58): 1-107. DOI: 10.18590/euscorpius.2007.vol2007.iss58.1.

Mohseni A, Vazirianzadeh B, Hossienzadeh M, Salehcheh M, Moradi A, Moravvej SA. 2013. The roles of some scorpions, Hemiscorpius lepturus and An-droctonus crassicauda, in a scorpionism focus in Ramhormorz, southwestern Iran. J Insect Sci 13 (1): 1-12. DOI: 10.1673/031.013.8901.

Monod L, Lourenco WR. 2005. Hemiscorpiidae (Scorpiones) from Iran, with descriptions of two new species and notes on biogeography and phylogenetic relationships. Rev Suisse Zool 112 (4): 869-942. DOI: 10.5962/bhl.part.80331.

Mousavi H, Navidpour S, Rafinejad J. 2015. A review study on distribution and medical importance of Hemiscorpius Peters, 1861 in Iran. J Mazandaran Univ Med Sci 24 (120): 107-124.

Navidpour S, Soleglad ME, Fet V, Kovařík F. 2013. Scorpions of Iran (Arachnida, Scorpiones). Part IX. Hormozgan province, with a description of Odontobuthus tavighiae sp. n. (Buthidae). Euscorpius 2013 (170): 1-29. DOI: 10.18590/euscorpius.2013.vol2013.iss170.1.

Navidpour S. 2012. A review study on Hottentotta Birula, 1908, (Scorpionida: Buthidae) species collected from Iran. Arch Razi Inst 67 (2): 93-100.

Navidpour S. 2015. An annotated checklist of scorpions in south and southwestern parts of Iran. Int J Fauna Biol 2 (3): 9-15. 
Nazari M, Hassan R. 2016. Study on distribution of scorpions to provide prevention and interventions in combating scorpionism in Poldokhta county, Lorestan province, Iran. J Clin Diagn Res Title: JCDR 10 (12): LC05-LC09. DOI: 10.7860/JCDR/2016/22759.8960.

Nejati J, Mozafari E, Saghafipour A, Kiyani M. 2014. Scorpion fauna and epidemiological aspects of scorpionism in southeastern Iran. Asian Pac J Trop Biomed 4: S217-S221. DOI 10.12980/APJTB . 4.2014C1323.

Pardal PPdO, Castro LC, Jennings E, Pardal JSdO, Monteiro MRdCdC. 2003. Epidemiological and clinical aspects of scorpion envenomation in the region of Santarém, Pará, Brazil. Rev Soc Bras Med Trop 36 (3): 349-353. DOI: 10.1590/S0037-86822003000300006.

Pipelzadeh MH, Jalali A, Taraz M, Pourabbas R, Zaremirakabadi A. 2007. An epidemiological and a clinical study on scorpionism by the Iranian scorpion Hemiscorpius lepturus. Toxicon 50 (7): 984-992. DOI 10.1016/j.toxicon.2007.07.018.

Prendini L, Wheeler WC. 2005. Scorpion higher phylogeny and classification, taxonomic anarchy, and standards for peer review in online publishing. Cladistics 21 (5): 446-494. DOI: 10.1111/j.10960031.2005.00073.x.

Radmanesh M. 1990. Clinical study of Hemiscorpion lepturus in Iran. J Trop Med Hyg 93 (5): 327-332.

Rafizadeh S, Rafinejad J, Rassi Y. 2013. Epidemiology of scorpionism in Iran during 2009. J Arthropod Borne Dis 7 (1): 66-70.

Rahmani A, Jalali A. 2012. Symptom patterns in adult patients stung by scorpions with emphasis on coagulopathy and hemoglubinuria. J Venom Anim Toxins incl Trop Dis 18 (4): 427-431. DOI: 10.1590/S1678-91992012000400011.

Saghafipour A, Noroozi M, Jooshin MK. 2013. The epidemiologic status of scorpion stings in Qom Province, 2001-2011. J Safe Promot Inj Prev 1 (2): 95-101.
Shahbazzadeh D, Amirkhani A, Djadid ND, Bigdeli S, Akbari A, Ahari H, Amini H, Dehghani R. 2009. Epidemiological and clinical survey of scorpionism in Khuzestan province, Iran (2003). Toxicon 53 (4): 454459. DOI: 10.1016/j.toxicon.2009.01.002.

Shahi M, Azizi K, Ansarian N. 2009. Study on scorpions fauna in high risk area of Hormozgan province, 2006-7. Hormozgan Medical Journal: HMJ 12 (4): 207-214.

Shahi M, Moosavy SH, Hanafi-Bojd AA, Navidpour S, Zare S, Madani A, Rafinejad J. 2016. Spatial distribution of scorpion sting in a high-risk area of southern Iran. J Med Entomol 53 (5): 1198-1204. DOI: 10.1093/jme/tjw043.

Shahi M, Rafinejad J, Az-Khosravi L, Moosavy SH. 2015. First report of death due to Hemiscorpius acanthocercus envenomation in Iran: Case report. Electron Physician 7 (5): 1234.

Talebian A, Doroudgar A. 2006. Epidemiologic study of scorpion sting in patients referring to Kashan medical centers during 1991-2002. Iran J Clin Infect Dis 1 (4): 191-194.

Uluğ M, Yaman Y, Yapici F, Can-Uluğ N. 2012. Scorpion envenomation in children: An analysis of 99 cases. Turk J Pediatr 54 (2): 119-127.

Vazirianzadeh B, Hossienzadeh M, Moravvej S, Vazirianzadeh M, Mosavi S. 2013. An epidemiological study on scorpion stings in Lordegan County, south-west of Iran. Arch Razi Inst 68 (1):71-76.

Vazirianzadeh B, Salahshoor A. 2015. Scorpion sting in Izeh, Iran: an epidemiological study during 2009-2011. J Basic Appl Sci 11: 403409. DOI: 10.6000/1927-5129.2015.11.57.

Zare MA., Mahmoodi KS, Teimoorzadeh S. 2011. Antivenom injection time related effects of Hemiscorpius lepturus scorpion envenomation in rabbits. Arch Razi Inst 66 (2):139-145. 